\title{
Collaborating with Students to Create Law Assessment: A Case Study
}

\author{
ALEX DEAGON*
}

\begin{abstract}
Many students are driven by their perceptions of assessment, and consequently, assessment can be used as a tool to enhance the learning process. The increased focus on student-centred learning in this context has resulted in student involvement in assessment. However, the literature in law focuses primarily on self-assessment and peer assessment, or criteria and marking, rather than student involvement in the creation of assessment content. This article investigates collaborative assessment in the context of legal education by undertaking a case study of staff collaborating with students to create the content of assessment in the undergraduate law subject 'Evidence' at the Queensland University of Technology. The case study found through surveys that when students have a degree of choice in the creation of assessment, they feel more confident, engaged and motivated to complete the assessment. Students felt this enhanced their learning experience. This study adds to the literature on student involvement in assessment by specifically considering collaborative assessment in law, which can then inform teaching practices with the aim of enhancing the learning experience for students.
\end{abstract}

\section{Introduction}

It is well known that assessment strategy has a major impact on student learning and activity. Learning approaches are influenced by the learning environment, particularly the assessment. Student decisions about what and how to study are driven not by their understanding of the curriculum, but by their perceptions of the assessment requirements. ${ }^{1}$ Assessment is an integral part of the learning process and should 'generate confidence and enhance capacity for increasingly independent future learning' ${ }^{2}$ It follows that devising the assessment appropriately will increase intrinsic interest in and deep engagement with the subject matter, arguably enhancing learning outcomes. ${ }^{3}$ The development of innovative methods such as selfassessment and peer-assessment is a reflection of this and other conceptual

\footnotetext{
Lecturer, Faculty of Law, Queensland University of Technology.

Mary Heath, 'Assessment Strategies' in Sally Kift et al (eds), Excellence and Innovation in Legal Education (LexisNexis, 2011) 269, 270.

Ibid.

3 Sue Bloxham and Pete Boyd, Developing Effective Assessment in Higher Education (Open University Press, 2007) 17.
} 
shifts which reside in a discourse where power is increasingly being shared with students to develop their individual skills and autonomy. ${ }^{4}$

Specifically, Birenbaum has identified that rather than a teacher-centred learning approach where the role of the student is a passive receiver, students should be seen as active participants in both learning and assessment so that they can develop their autonomy and critical judgment. ${ }^{5}$ It is important to bear in mind that what the student does is actually more significant in determining what is learned than what the teacher does. Thus, it is important to persuade students to engage in learning activities in order to promote their own learning. ${ }^{6}$ Moreover, 'as assessment is a key area in facilitating and motivating students it [is] important to allow students the opportunity to develop their learning in a relevant area of their choice'. ${ }^{7}$ In other words, the argument is giving students some control over their area of learning and linking that area directly with assessment will motivate students and help them to develop their learning.

This article proposes that one way to do this is to have staff collaborate with students to create the content of assessment. Specifically, this article investigates the procedure of allowing students direct input into the development of and choice between essay topics as part of their final exam in a core law subject. Since it is well established that assessment guides and motivates student learning, it follows that collaborating with students to create assessment in this way should have a positive qualitative effect on their learning experience (and perhaps also a quantitative effect in terms of grade improvement), since they will have intrinsic motivation to study and prepare. ${ }^{8}$ Here learning experience refers to student engagement with the process and structures of learning. This is consistent with the work in selfdetermination theory which argues that self-motivated and self-determined behaviour is linked to psychological well-being. ${ }^{9}$ Thus, in the pedagogical

4 Sally Brown and Angela Glasner, 'Towards Autonomous Assessment' in Sally Brown and Angela Glasner (eds), Assessment Matters in Higher Education(Open University Press, 1999) 157, 157-8.

5 M Birenbaum, 'Assessment 2000: Towards a pluralistic approach to assessment' in Menucha Birenbaum and Filip J R C Dochy (eds), Alternatives in Assessment of Achievements, Learning Processes and Prior Knowledge (Kluwer, 1996). See also David Boud and Nancy Falchikov, Rethinking Assessment in Higher Education Learning for the Longer Term (Routledge, 2007).

6 Janis Moody, 'An Integrated Approach to Learning, Teaching and Assessment in a Healthcare Ethics Module' in Steve Frankland (ed), Enhancing Teaching and Learning through Assessment: Deriving an Appropriate Model(Springer, 2007) 78, 79.

7 Ibid 82 . In relation to a collaborative enquiry by staff and students on effective assessment feedback practices, see also Will Curtis, 'Assessment Reassessed: A student and lecturer collaborative (Case Hquiry' Study, Higher Education Academy, 1 December 2011) < https://www.heacademy.ac.uk/resources/detail/res ources/detail/subjects/escalate/8141 Assessment Reassessed- A stude>.

8 See, eg, Maarten Vansteenkiste, Willy Lens and Edward Deci, 'Intrinsic Versus Extrinsic Goal Contents in Self-Determination Theory: Another Look at the Quality of Academic Motivation' (2006) 41(1) Educational Psychologist 19; Raymond J Wlodkowski, Enhancing Adult Motivation to Learn (Wiley, $3^{\text {rd }}$ ed, 2011).

9 See, eg, Christopher P Niemiec, Richard M Ryan and Edward L Deci, 'Self-determination Theory and the Relation of Autonomy to Self-regulatory Processes and Personality 
context, self-determination theory implies that autonomous and independent learning is linked to student well-being and success in the learning experience. ${ }^{10}$ The relative lack of literature exploring this phenomenon in law, and the particular permutation of collaborating with students to create the content of the assessment, presents a unique opportunity to consider the claim that this kind of collaborative assessment has the stakeholder benefits indicated by the literature. The immediate key stakeholders in this context are the students enrolled in LLB303 Evidence Semester 2 (July-November) 2016, which is an undergraduate third-year core law subject at the Queensland University of Technology, and the unit coordinator facilitating the collaborative assessment item. Indirect stakeholders are students generally, including law students, and all staff involved in the design of assessment intended to motivate students and enhance learning.

Therefore, the rationale for this article is to examine whether collaborating with students in the creation of law assessment enhances student learning by increasing their motivation and approach to preparing for the assessment. This is important for the field because it would add to the general literature in conjunction with significantly contributing to the legal literature in the area. The article will attempt to provide evidence for continuing a student-empowered approach to curriculum and assessment design in legal education. It will suggest that student attitudes and approaches towards assessment benefit from student involvement in the creation of that assessment through giving them autonomy and power in the design process.

The article is structured as follows. A Literature Review will outline the relevant literature, identifying a significant gap when it comes to innovative and collaborative assessment. Though there is much literature concerning the involvement of students in assessment through the development of criteria and the process of marking, there is limited literature on involving students through the collaborative creation of content. This method of collaboration arguably addresses some of the shortcomings of the other methods and requires further investigation. The article proceeds to outline the methodology and methods undergirding of a preliminary investigation, which occurred in the second half of 2016 in relation to an undergraduate law subject. The results are displayed, and basic descriptive analysis indicates there is evidence to support the

Development' in R Hoyle (ed), Handbook of Personality and Self-Regulation (WileyBlackwell, 2010) 169; Richard M Ryan and Edward L Deci, 'Self-Determination Theory and the Facilitation of Intrinsic Motivation, Social Development and Well-Being' (2000) 55(1) American Psychologist 68.

10 See, eg, Christopher P Niemiec and Richard M Ryan, 'Autonomy, Competence, and Relatedness in the Classroom: Applying self-determination theory to educational practice' (2009) 7(2) Theory and Research in Education 133; Feryal Cubukcu, 'Learner Autonomy, Self Regulation and Metacognition' (2009) 2(1) International Electronic Journal of Elementary Education 53. For similar arguments in relation to self-regulated learning, see Monique Boekaerts, 'Self-Regulated Learning: A new concept embraced by researchers, policy makers, educators, teachers and students' (1997) 7(2) Learning and Instruction 161. 
contention that this method of collaboration can enhance student motivation and learning experience as perceived by students. The article concludes by noting that this case study adds to the relevant literature, but further research is necessary to confirm and strengthen the reliability and validity of the results.

\section{Literature Review}

\section{A Assessment and Curriculum: Student-centred Learning}

Assessment is about selecting tasks to suit how we want students to learn, and selecting criteria telling us what and how well they have been learned. This project occurs according to the 'standards' model of assessment, where teachers get students to engage in activities which are likely to result in the effective learning of intended outcomes. ${ }^{11}$ Learning and assessment have traditionally been seen as distinct activities. However, there is now the recognition that the method of assessment influences the learning; assessment and learning are integrated activities. ${ }^{12}$ Assessment frames learning, creates learning activity and orientates all aspects of learning behaviour. ${ }^{13}$ Students learn what they believe they will be examined on, and the assessment determines what students learn more than the curriculum itself. Therefore, the assessment strategy and criteria must be aligned to subject objectives, subject content and teaching and learning activities, and this alignment needs to be embedded at the curriculum level and clearly communicated to students. ${ }^{14}$ The correspondence between the act of learning and the assessment of learning (incorporating the learning activities into the assessment tasks) is known as constructive alignment, and is 'widely accepted' as the most appropriate method. ${ }^{15}$

Assessment is at the heart of the student experience; it defines what and how students learn. ${ }^{16}$ It has been said that 'if you want to change student learning then change the methods of assessment'. ${ }^{17}$ Thus, 'assessment practice in law can be positively harnessed to better engage, motivate and

11 Steve Frankland (ed), Enhancing Teaching and Learning through Assessment: Deriving an Appropriate Model (Springer, 2007) xxiii-1.

12 Brown and Glasner, above $\mathrm{n} 4$.

13 Graham Gibbs, 'How Assessment Frames Student Learning' in Cordelia Bryan and Karen Clegg (eds), Innovative Assessment in Higher Education (Routledge, 2006) 23.

14 Steve Frankland, 'Perspectives of Teachers and Students towards Assessment' in Steve Frankland (ed), Enhancing Teaching and Learning through Assessment: Deriving an Appropriate Model (Springer, 2007) 66; Roger Murphy, 'Evaluating New Priorities for Assessment' in Cordelia Bryan and Karen Clegg (eds), Innovative Assessment in Higher Education (Routledge, 2006) 37, 42.

15 Frankland, above n 11, xxiii-1.

16 Murphy, above n 14, 68.

17 George Brown, Joanna Bull and Malcolm Pendlebury, Assessing Student Learning in Higher Education (Routledge, 1997) 7. 
support students in their learning'. ${ }^{18}$ One strategy is using assessment as a teaching and learning tool in order to encourage students to be independent, critical and engaged learners. ${ }^{19}$ The idea is that providing students with more autonomy will motivate them to learn more effectively and more deeply.

This is vital for the tertiary teaching context. The teaching function of universities includes the development of a student's critical abilities and the development of a student's autonomy. Consequently, as already noted in the Introduction, there has been a shift in rhetoric from teacher-centred to student-centred learning environments, 'placing greater emphasis on the need to encourage students to take responsibility for their own learning' ${ }^{20}$ This involves 'recognition of the need to empower learners within the teaching and learning contract'. ${ }^{21}$ The rhetoric corresponds with a new assessment culture having elements which include students constructing knowledge rather than merely reproducing it and active involvement in the assessment process through innovative or autonomous assessments. ${ }^{22}$ There is a 'growing recognition that adult learners have a legitimate role in assessment partnership'. ${ }^{23}$ Furthermore, teachers need to change their perceptions of their role as the repository of all knowledge and an absolute authority on matters of assessment. ${ }^{24} \mathrm{~A}$ dialogue between learners and teachers is developing. The power differential between teachers and students is being broken down as both aspire to improve. ${ }^{25}$ Empowerment can occur when 'an individual learner can be empowered to make decisions about a course of action'. ${ }^{26}$ Practically, this has meant a shift from assessment being set and assessed by the teacher alone to the allowance for some student choice and control through innovative and autonomous assessments. $^{27}$

18 Penelope Watson and Rachel Field, 'Promoting Student Well-Being and Resilience at Law School' in Sally Kift et al (eds), Excellence and Innovation in Legal Education (LexisNexis, 2011) 389, 406. See generally Moody, above n 6.

19 Watson and Field, above n 18, 408-9.

20 Lorraine Stefani, 'Peer- and Self-Assessment - Drawing the Parallels Between Student and Staff Practice' in Steve Frankland (ed), Enhancing Teaching and Learning through Assessment: Deriving an Appropriate Model(Springer, 2007) 119.

21 Ibid.

22 Cordelia Bryan and Karen Clegg, 'Reflections, Rationales and Realities' in Cordelia Bryan and Karen Clegg (eds), Innovative Assessment in Higher Education (Routledge, 2006) 216, 217.

23 Linda Leach, Guyon Neutze and Nick Zepke, 'Assessment and Empowerment: Some critical questions' (2001) 26(4) Assessment and Evaluation in Higher Education 293, 293. See also David McConnell, 'The Experience of Collaborative Assessment in e-Learning' (2002) 24(1) Studies in Continuing Education 73.

24 Nancy Falchikov, Improving Assessment through Student Involvement (Routledge, 2005) 62, 151-2.

25 Bryan and Clegg, above n 22, 225.

26 Falchikov, 'Improving Assessment', above n 24, 127; Leach, Neutze and Zepke, above n 23, 296.

27 Brown, Bull and Pendlebury, above n 17, 15-6. 


\section{B Innovative Assessment}

Innovative or alternative assessment was developed in this dynamic context when it was felt that the traditional modes of assessment failed to accurately represent student knowledge and understanding, and failed to develop necessary graduate attributes. ${ }^{28}$ Innovative assessment can be considered as such if it is new in the context where it is adopted, and/or if it attempts to do something different. ${ }^{29}$ In this case, it is the idea of actively involving students in the assessment process. The rationale is to help students engage by producing intrinsic motivation. Involving students and seeking their input in this way is part of the beneficial process of giving students more freedom, responsibility and autonomy so that they develop as learners. ${ }^{30}$ However, it is important that the reasons for adopting innovative assessment are carefully explained to students and that the implementation is circumspect. Fully informing students about the reasons for the assessment and implementing it in a considered way will help empower students, improving their learning experience and satisfaction. ${ }^{31}$

Student approaches to assessment are strongly influenced by their perceptions of the task. Helping students understand the purpose and rubric of innovative methods will help them to engage and develop procedural autonomy (the ability for students to manage their own studies). Since students consider that clarity and openness are fundamental criteria for a fair and valid assessment system, preparing students for assessment should involve students in active ways. ${ }^{32}$ Students are 'generally positive' about innovative assessments where they are 'involved as active and informed participants'. ${ }^{33}$

Moreover, some students have a negative attitude towards traditional assessment because they perceive it to be unfair, and this perception may stem from the power relations inherent in traditional assessment. 'Students typically have little or no say in the setting of assignments' ${ }^{34}$ As has been discussed, students' interest and approach to studying are strongly related to their experiences of teaching and assessment. Lack of interest or poor motivation arises from a context, rather than being an intrinsic attribute. One of the weaknesses of traditional assessment is that 'students may become alienated by the non-participative assessment processes they have

28 Liz McDowell and Kay Sambell, 'The Experience of Innovative Assessment: Student Perspectives' in Sally Brown and Angela Glasner (eds), Assessment Matters in Higher Education (Open University Press, 1999) 71.

29 Rosario Hernandez, 'The Impact of Innovative Assessment Practices on Students' Learning' in Steve Frankland (ed), Enhancing Teaching and Learning through Assessment: Deriving an Appropriate Model (Springer, 2007) 267.

30 McDowell and Sambel, above n 28, 72-9.

31 Ibid; McConnell, above n 23, 77-81.

32 Bloxham and Boyd, above n 3, 69-72. For a discussion of assessment validity from a pedagogical perspective, see Eleanore Hargreaves, 'The Validity of Collaborative Assessment for Learning' (2007) 14(2) Assessment in Education: Principles, Policy and Practice 185.

33 Bloxham and Boyd, above n 3, 190.

34 Falchikov, 'Improving Assessment', above n 24, 35. 
experienced. Alienation too readily translates into lack of motivation... effective learning requires that learners be able to influence their own learning. ${ }^{35}$ The fact that learners typically have little or no control over traditional assessment processes therefore compels them to be passive consumers of whatever is thrust upon them. ${ }^{36}$ Giving students more choice increases their 'ownership and commitment' in regard to the content and their learning. ${ }^{37}$ As Brew argues:

When teachers share with their students the process of assessment — giving up control, sharing power and leading students to take on the authority to assess themselves - the professional judgment of both is enhanced. Assessment becomes not something done to students. It becomes an activity done with students. ${ }^{38}$

According to Bloxham and Boyd, the result is 'students come to have a better understanding of the subject matter and their own learning through their close involvement with assessment'. ${ }^{39}$ Through conversations and feedback between student and teacher in relation to assessment, for the student 'a greater degree of ownership and responsibility is developed, which leads to greater independence and autonomy in their learning'. ${ }^{40}$ Assessment can therefore be redefined as an instrument of liberation, rather than objective judgement or limitation. ${ }^{41}$ Hence, innovative assessment is successful when it allows students to gradually build the skills of autonomy, self-regulated learning and judgments, encouraging them to critically reconceptualise the nature of assessment and learning. ${ }^{42}$ Peer and self-assessment are examples of this kind of innovative assessment which aims to promote, practice and develop student autonomy as an outcome..$^{43}$

\section{Peer and Self-assessment}

Peer and self-assessment involve students mutually giving and receiving feedback on the work of others with equal status, empowering learners and improving the quality of learning by allowing them to be involved in the

Ibid 36-7.

Ibid 37.

Brown, Bull and Pendlebury, above n 17, 15-6.

38 Angela Brew, 'Towards Autonomous Assessment: Using Self-Assessment and Peer Assessment' in Sally Brown and Angela Glasner (eds), Assessment Matters in Higher Education (Open University Press, 1999) 159, 169.

39 Bloxham and Boyd, above n 3, 15.

40 Alan Robinson and Mark Udall, 'Student Learning through Critical Reflection' in Cordelia Bryan and Karen Clegg (eds), Innovative Assessment in Higher Education (Routledge, 2006) 92.

41 Cordelia Bryan and Karen Clegg, 'Introduction' in Cordelia Bryan and Karen Clegg (eds), Innovative Assessment in Higher Education (Routledge, 2006) 1, 1-2.

42 Kay Sambell, Liz McDowell and Alistair Sambell, 'Developing Learner Autonomy via Assessment' in Cordelia Bryan and Karen Clegg (eds), Innovative Assessment in Higher Education (Routledge, 2006) 158, 166; Bryan and Clegg, 'Introduction', above n 41, 1-2.

43 Sambell, McDowell and Sambell, above n 42, 158-9. 
assessment process. ${ }^{44}$ There are numerous benefits of allowing students to gain autonomy in the assessment process, including 'giving a sense of ownership of the assessment process, and improving motivation', 'encouraging students to take responsibility for their own learning' and 'facilitating student-centred learning' ${ }^{45}$ However, there are a number of well-documented problems with peer and self-assessment, including student anxiety about being assessed by their peers due to lack of confidence in their ability to assess, student subjectivity resulting in overly critical or overly generous marks, and differences in ratings between students and staff. 46 While self and peer assessment can increase motivation and professional development, they make consistency and fair comparison across the group more difficult to achieve. ${ }^{47}$

One possible reason for student reluctance to engage in innovative assessment is the power differential between teachers and students, in which the views of the teacher are regarded as beyond discussion. Peer assessment involves the recognition that to assess is to have power over a person. Assessment is the quintessential embodiment of power relations between teachers and students. ${ }^{48}$ Sharing the assessment is to share the power of the teacher to encourage students to take responsibility for their learning. However, students dislike having power over each other. ${ }^{49}$ As Falchikov argues, students specifically dislike having to mark their peers, and friendships or tensions can result in overly generous or overly critical grades. Students also question their ability and competence to engage in peer assessment, and often do not know where to start. ${ }^{50}$

44 Steve Frankland, 'Peer Assessment among Students in a Problem-Based Learning Format' in Steve Frankland (ed), Enhancing Teaching and Learning through Assessment: Deriving an Appropriate Model(Springer, 2007) 145.

45 Ibid 145. See also Hugh Somervell, 'Issues in Assessment, Enterprise and Higher Education: The case for peer and self-peer and collaborative assessment' (1993) 18(3) Assessment and Evaluation in Higher Education 221. For an example of a project which facilitates deep learning and improves student engagement through collaborative, self-directed assessment, see Melissa Miles and Sarah Rainbird, 'Rethinking Assessment to Enhance Interdisciplinary Collaborative Learning in the Creative Arts and Humanities' (Final Report, Office for Learning and Teaching, Australian Government, 2013) <http://www.olt.gov.au/resourcerethinking-assessment-creative-arts-humanities>. However, this project did not focus on students creating assessment. For a detailed discussion of the issues see Keith Willey, 'Improving Learning and Developing Professional Judgment in Large Classes Through Collaboration and Self and Peer Assessment' (Office for Learning and Teaching, Australian Government, 2014) <http://www.olt.gov.au/resource-improving-learning-developingprofessional-judgement-through-collaborative-self-peer-assessment>; Falchikov, 'Improving Assessment', above n 24.

46 Frankland, 'Peer Assessment', above n 44, 145; See, eg, David Boud, Ruth Cohen and Jane Sampson 'Peer Learning and Assessment' (1999) 24(4) Assessment and Evaluation in Higher Education 413; Lorraine A J Stefani, 'Peer, Self and Tutor Assessment: Relative Reliabilities' (1994) 19(1) Studies in Higher Education 69.

47 Brown, Bull and Pendlebury, above n 17, 16, 173.

48 McConnell, above n 23, 77.

49 Brew, above n 38, 161.

s0 Falchikov, 'Improving Assessment', above n 24, 67. 
Moreover, peer and self-assessment can actually disempower students where the action or process is imposed by the teacher, reasserting teacher dominance. Genuine empowerment occurs when aspects of the assessment content, process and/or criteria are made optional; in other words, where students are given an autonomous choice as to their role in the assessment. ${ }^{51}$ For example, in one study of third-year students in the School of Computer Science and Electrical Engineering in the University of Queensland, peer assessors allocating grades were trusted to be responsible, but they were recommendations only, and the lecturer had the final say. Here there is some indication of power transfer, but with reluctance and the suggestion of uncertainty. Nevertheless, even this limited transfer of power may have contributed to the fact that some students questioned the objectivity of the process - 'the first step to emancipation'. 52 Thus, 'the quality of learning and assessment is enhanced... when students take ownership of their learning and assessment'.53

Peer and self-assessment provide a greater sense of accountability, motivation and responsibility, as well as increasing understanding of the subject matter. Furthermore, other commentators have argued the concerns about peer and self-assessment such as subjectivity and inconsistency of marking have not been borne out by the research, which has generally found good levels of agreement between staff and students when there is specific training and the marking is based on criteria; sometimes the agreement is even better than the level of difference between internal and external examiners. Other studies have shown that strategies such as double blind peer marking and more detailed grading scales have been successful. ${ }^{54} \mathrm{~A}$ meta-analysis of peer assessment studies indicates that most problems may be overcome through the consistent involvement of students in the development of clear and specific criteria, careful preparation and planning, an open dialogue with students as the assessment develops, and combining peer assessment with self-assessment and coassessment. ${ }^{55}$

\section{Collaborating to Create Assessment Content}

The vast majority of literature on innovative assessment and involving students in assessment focuses uniquely on peer and self-assessment, and/or determination of criteria and marking, rather than the actual creation

Ibid 127.

52 Ibid 133. See Helen C Purchase, 'Learning about Interface Design through Peer Assessment' (2000) 25(4) Assessment and Evaluation in Higher Education 341.

53 Falchikov, 'Improving Assessment', above n 24, 149.

54 Bloxham and Boyd, above n 3, 23, 191. See, eg, Falchikov, 'Improving Assessment', above n 24; Brown, Bull and Pendlebury, above n 17, 171, 180.

55 Falchikov, 'Improving Assessment', above n 24, 190-8. See also F Dochy, M Segers and D Sluijsmans, 'The Use of Self-, Peer and Co-assessment in Higher Education: A review' (1999) 24(3) Studies in Higher Education 331; Stefani, above n 46; McConnell, above n 23, 78-83. 
of the assessment content itself. ${ }^{56}$ It can also involve the development of learning goals and learning contracts. ${ }^{57}$ Though the literature indicates that this type of collaboration between staff and students is beneficial in a broad sense, there is clearly also some dispute over the reliability and validity of peer and self-assessment where students are involved in the marking process. This article does not attempt to resolve these conflicting views. What can be said is that even if the alleged problems with peer and selfassessment are overstated, the advantage of the collaborative approach proposed by this article is that it involves students in assessment and provides the associated advantages of active student involvement in the assessment without the potential problems of students assessing themselves or other students. The collaborative assessment approach proposed is that students collaborate with staff in the process of creating the content to be assessed - specifically, involvement in creating the form and content for an essay question in the final exam. There is limited literature considering such an approach.

Collaborative assessment, also known as 'co-assessment' or 'participative assessment', is usually used to indicate that students and teachers 'share the responsibility for selecting criteria' and participate in assessment as a 'joint effort'. ${ }^{58}$ Studies have documented positive results when students are 'actively involved' in assessment 'offering elements of choice, control and responsibility' through collaborating with staff. 59 The version of collaborative assessment this project proposes (collaborating with students in the creation of assessment) is a way of involving students in the assessment process while allowing staff to retain the necessary control over final marking for validity and reliability. It can be seen as a teaching and learning process where the students collaborate with staff in determining the content of what will be assessed. In other words, allowing students to choose the content of assessment while the marking remains with staff increases student autonomy without compromising the validity or reliability of the results. This version of collaborative assessment is thus unique in the sense that it focuses on students collaborating to develop the content of assessment, not the criteria against which the assessment is judged or the process of assessing itself (marking).

The fact that students study according to what they believe about assessment has important implications for collaborative assessment. If students are collaborating with staff and are actively involved in decisions about the assessment process, this intrinsic interest will arguably have a positive qualitative effect on the relationship between students and their

56 See, eg, Boud, Cohen and Sampson, above n 46; Stefani, above n 46.

57 Falchikov, 'Improving Assessment', above n 24, 126.

58 Falchikov, 'Improving Assessment', above n 24, 125. See also Nancy Falchikov, 'Product Comparisons and Process Benefits of Collaborative Self and Peer Group Assessments' (1986) 11(2) Assessment and Evaluation in Higher Education 146; Michael Reynolds and Kiran Trehan, 'Assessment: A critical perspective' (2000) 25(3) Studies in Higher Education 267.

59 Sambell, McDowell and Sambell, above n 42, 166. 
studies. ${ }^{60}$ A positive social climate or 'learning community' is a major factor in the effectiveness of collaborative assessment. ${ }^{61}$ In this context, the teacher exists 'between the boundary of the institution' and the 'learning community' ${ }^{62}$ The teacher 'adopts the role' of 'teacher-participant', which 'implies a sharing of power with course participants' ${ }^{63}$ The teacher works to ensure that 'power is transferred to the participants in the community, who in turn have to come to trust' the teacher. ${ }^{64}$ 'Power is shared along a series of dimensions such as decision making about the focus' of assessment. Teachers and students 'relate in highly personal ways', which shapes the course learning. ${ }^{65}$ Thus, teachers sharing power with students in the form of control over the assessment helps build a positive learning community which arguably enhances learning outcomes. These elements of collaborative assessment are generally applicable to any discipline, but the case study in this article has occurred in the context of legal education. The article therefore turns to consider assessment generally and collaborative assessment in law.

\section{E Collaborative Assessment in Law}

As with tertiary study in all other disciplines, assessment is at the centre of the learning experience in law. It should reflect what students have achieved and help them to reach their potential as learners. Assessment should be 'rigorous, authentic, reliable and fair', reflecting long established academic standards and approved by students, academic peers, universities and the legal profession. ${ }^{66}$ Typically, summative law assessment tests the legal reasoning process of students through creating hypothetical factual scenarios which examine students' ability to identify issues, apply the relevant law to the scenario, and construct appropriate legal arguments for an imaginary client. Occasionally, exams include the assessment of deeper critical engagements with fundamental questions undergirding specific areas of law through essays. ${ }^{67}$ The relationship between curriculum and assessment is essential. Heath quips that "if the perspective of the "bad man" (or the "bad woman") tells us what the law is - according to legal

60 See, eg, Maarten Vansteenkiste, Willy Lens and Edward Deci, 'Intrinsic Versus Extrinsic Goal Contents in Self-Determination Theory: Another Look at the Quality of Academic Motivation' (2006) 41(1) Educational Psychologist 19; Raymond J Wlodkowski, Enhancing Adult Motivation to Learn (Wiley, $3^{\text {rd }}$ ed, 2011).

61 McConnell, above n 23, 76.

62 Ibid.

63 Ibid.

64 Ibid.

65 Ibid.

66 Susan Armstrong and Judith McNamara, 'Transition Pedagogy in First and Final Year Law Programs' in Sally Kift et al (eds), Excellence and Innovation in Legal Education(LexisNexis, 2011) 207, 232. See also William M Sullivan et al, Educating Lawyers: Preparation for the Profession of Law (Jossey-Bass, 2007); Roy Stuckey et al, Best Practices for Legal Education: $A$ Vision and a Road Map (Clinical Legal Education Association, 2007).

67 See T A Downes, P R Hopkins and W M Rees, 'Methods of Assessment in British Law Schools' (1982) 16(3) The Law Teacher 77. 
realism - then assessment tells students what the curriculum is according to education research' ${ }^{68}$ In other words, students study and learn according to what they perceive the assessment to be. Constructive alignment and positive teaching approaches to assessment will therefore contribute to enhanced learning outcomes. 69

Referring to self-determination theory in the context of legal education, Field, Duffy and Huggins note that even though independent learning involving autonomy and active self-direction is a key element in tertiary success for law, it is not usually a skill that is taught or developed in the classroom. This leads to student dissatisfaction and limits beneficial learning outcomes. ${ }^{70}$ They argue that learning environments and curriculum should be developed to support autonomous, self-regulated learning; this will 'promote student learning, academic performance and well-being', and increase the likelihood that students will be 'motivated towards deep learning and mastery' which fosters 'engagement, creativity and academic performance'. ${ }^{71}$ They make some strategic and practical suggestions which are not directly related to assessment. ${ }^{72}$

However, since 'assessment is a critical point of contact, influence and engagement with students', assessment too can be strategically and practically designed to improve student engagement and resilience. ${ }^{73}$ One strategy for promoting student wellbeing and consequently enhancing student learning outcomes is designing assessment which encourages students to be independent learners. ${ }^{74}$ Encouraging innovative and studentcentred assessment, such as self-assessment or peer assessment, helps develop self-regulated learning and student-teacher dialogue about learning. ${ }^{75}$ This should eventually proceed from teacher driven feedback to

68 Mary Heath, 'Assessment Strategies' in Sally Kift et al (eds), Excellence and Innovation in Legal Education (LexisNexis, 2011) 269, 270.

69 Ibid 276-9.

70 Rachel Field, James Duffy and Anna Huggins, 'Teaching Independent Learning Skills in the First Year: A positive psychology strategy for promoting law student well-being' (2015) 7(2) Journal of Learning Design 26, 28-9. See, eg, Kennon M Sheldon and Lawrence S Krieger 'Understanding the Negative Effects of Legal Education on Law Students: A Longitudinal Test of Self-Determination Theory' (2007) 33 Personality and Social Psychology Bulletin 883.

71 Field, Duffy and Huggins, above n 70, 31. See also Anna Huggins, 'Autonomy Supportive Curriculum Design: A salient factor in promoting law students' wellbeing' (2012) 35(3) University of New South Wales Law Journal 683; Michael Hunter Schwartz, Expert Learning for Law Students (Carolina Academic Press, $2^{\text {nd }}$ ed, 2008); Michael Hunter Schwartz, Sophie M Sparrow and Gerald F Hess, Teaching Law by Design: Engaging Students from the Syllabus to the Final Exam (Carolina Academic Press, 2009).

72 Field, Duffy and Huggins, above n 70, 31-3.

73 Watson and Field, above n 18, 406. See generally Berry O'Donovan, 'Cultivating a Community of Assessment Practice to Enhance Students' Academic Performance' (Case Study, Hospitality, Leisure, Sport and Tourism Network, The Higher Education Academy, 2010) <https://www.heacademy.ac.uk/resource/cultivating-community-assessment-practiceenhance-students-academic-performance>.

74 Watson and Field, above n 18, 408-9

75 An example is the 'assessable class participation' strategy promoted in Alex Steel, Julien Laurens and Anna Huggins, 'Class Participation as a Learning and Assessment Strategy in Law: Facilitating Students' Engagement, Skills Development and Deep Learning' (2013) 
self-reliance and sustainable learning. ${ }^{76}$ Assessment could be designed to 'provide students with choice and enable them to take control of aspects of their own learning - for example, in relation to topic, timing of submission, method, weighting, or assessment criteria'. ${ }^{77}$ This call for designing law assessment which allows students to have a degree of control is precisely what this article proposes in the form of collaborating with students to create the assessment.

Although much of the general literature on collaborative assessment is applicable to a wide range of disciplines including law, the literature which specifically discusses collaborative assessment in law is limited. The literature that exists broadly emphasises the importance of engagement, participation, collaboration, inclusion, respect and autonomy for students in the curriculum to achieve enhanced learning outcomes. ${ }^{78}$ An example is Zimmerman's detailed discussion of collaborative and cooperative learning in the law curriculum. ${ }^{79}$ The article focuses primarily on collaborative learning, but does briefly discuss assessment. ${ }^{80}$ Zimmerman observes that core collaborative theory indicates that assessment and learning will improve through peer review processes. ${ }^{81} \mathrm{He}$ further notes the benefits of sharing the assessment process with students, particularly focusing on the development of the criteria for assessment. These benefits include 'clarity', 'sharing authority', and the 'gain in understanding'. ${ }^{82}$ Similarly, Murdoch discusses self and peer-assessment, noting that studentled curriculum and assessment is 'relatively unorthodox' in law but can facilitate deep learning and the enhancement of graduate attributes. ${ }^{83}$ However, there is no mention of creating assessment or collaborative development of assessable content.

36(1) University of New South Wales Law Journal 30. Such an approach has the benefit of promoting collaboration between students to enhance learning. However, it is not collaborative in the sense of collaboration between students and staff to create assessment and consequently the advantages of autonomous and deep learning are less pronounced.

76 Armstrong and McNamara, above n 66, 234-5.

77 Watson and Field, above n 18, 408-9.

78 See, eg, Paula Baron, 'Deep and Surface Learning: Can teachers really control student approaches to learning in law?' (2002) 36(2) The Law Teacher 123; Wendy Davis, 'Collaborating with Students as Co-authors' (2013) 47(1) The Law Teacher32; Jim Murdoch, 'Using Self- and Peer Assessment at Honours Level: Bridging the gap between law school and the workplace' (2015) 49(1) The Law Teacher 73, 73. See also Karen Hinett et al, 'Managing Change in Assessment and Learning in Legal Education: A tale of two cities' (1999) 33(2) The Law Teacher 135; Clifford Zimmerman, "Thinking Beyond My Own Interpretation": Reflections on Collaborative and Cooperative Learning Theory in the Law School Curriculum' (1999) 31 Arizona State Law Journal 957; Gerald Hess, 'Heads and Hearts: The Teaching and Learning Environment in Law School' (2002) 52 Journal of Legal Education 75.

79 Zimmerman, above n 78.

80 Ibid 982-5, 1011-4.

81 Ibid 1011-2.

82 Ibid 1013.

83 Murdoch, above n 78, 73. Hinett et al, above n 78 . 
Probably the most applicable piece is Hess' excellent analysis of the teaching and learning environment at law school. ${ }^{84}$ Although it is a general overview, Hess mentions the importance of engagement, participation, collaboration, inclusion, respect and autonomy for students to achieve enhanced learning outcomes. For student centred learning and assessment, 'the focus is on improving learning and helping students take responsibility for their learning' ${ }^{85}$ Hess also discusses the importance of feedback and includes self and peer assessment as methods of effective feedback. ${ }^{86}$

Hess specifically mentions collaborative course design, where students and teachers work together to design a subject. ${ }^{87}$ One way of involving students in course design is giving them choice in their assessment. 'Giving students options is one way to involve them in the course and to allow them to build on their strengths and interests... A more substantive involvement occurs when students choose topics for writing assignments. ${ }^{88}$ A potential disadvantage resulting from the limited technical knowledge students possess is a decrease in the complexity and rigour of the assessment. Nevertheless, allowing students to choose the topics they will be assessed on arguably increases their motivation, autonomy and critical judgment, thus enhancing their learning outcomes and learning experience; retaining staff oversight while incorporating student choice offsets the problem of students making the assessment too easy. Such an approach is favorably (though briefly) considered by Huggins, Kift and Field in the Australian context. ${ }^{89}$ They argue that assessment which allows a degree of choice 'encourage[s] law students' independent learning and autonomy'. 90 Corroborating the literature referred to earlier, Huggins, Kift and Field claim that giving students choice gives them a sense of 'empowerment', 'flexibility' and 'control', encouraging 'engagement'. ${ }^{91}$ As a 'practical strategy', they even suggest 'encouraging [students] to engage actively in assessment design' by 'drafting an essay topic' ${ }^{92}$ Therefore, this article seeks to supplement the general literature, and particularly the legal literature, by undertaking a case study of the 'substantive involvement' proposed by Hess or the 'practical strategy' suggested by Huggins, Kift and

84 Hess, 'Heads and Hearts', above n 78. See also Gerald F Hess, 'Student Involvement in Improving Law Teaching and Learning' (1998) 67 University of Missouri at Kansas City Law Review 343.

85 Hess, 'Heads and Hearts', above n 78, 109.

86 Ibid 106-7.

87 Ibid 96-8. For a detailed example including aspects of assessment design, see Gerald F Hess, 'Collaborative Course Design: Not My Course, Not Their Course, But Our Course' (2008) 47 Washburn Law Journal 367.

88 Hess, 'Heads and Hearts', above n 78, 97.

89 Anna Huggins, Sally Kift and Rachel Field, 'Implementing the Self-Management Threshold Learning Outcome for Law: Some International Design Strategies from the Current Curriculum Toolbox' (2011) 21 Legal Education Review 183.

$90 \quad$ Ibid 194.

91 Ibid 194-5.

92 Ibid 195. 
Field: allowing students to choose the topics of their essays in the final exam assessment with staff oversight.

\section{Methodology and Methods}

The methodology for this project was a case study. According to Yin, 'a case study is an empirical inquiry that investigates a contemporary phenomenon in depth and within its real-life context... [it] benefits from the prior development of theoretical propositions to guide data collection and analysis'. ${ }^{93}$ A case study may be more simply defined as an intensive analysis of an individual person or community stressing developmental factors in relation to environment. ${ }^{94}$ Stake notes that the individual person or community forms a 'functioning specific' or 'bounded system' which is defined by the casing..$^{95}$ A case analysis focuses on what is to be studied, aims to study that in depth, and contextualises the evolution or development of that case over time. Though it may involve the application of distinct methods, the case study is a methodology in its own right. 96

A case study produces concrete, context-dependent knowledge that research on learning shows to be necessary for the development of expertise ${ }^{97}$ Case studies are valuable at all stages of the theory-building process but are most valuable to test theories or hypotheses. ${ }^{98}$ "The advantage of the case study is that it can "close in" on real-life situations and test views directly in relation to phenomena as they unfold in practice.' 99 The case is a noun, thing or entity. To study a case is to understand the case, then carefully examine its function and activities before attempting to relate it to other cases. The case is the prime referent in the case study, not another method or methodology. Qualitative understanding of cases involves experiencing the activities of the case as it occurs in its particular situation. A case is dynamic, autonomous and operates in the real world. ${ }^{100}$

A case study methodology is appropriate if the research questions seek to explain how or why some social phenomenon works, and especially if the questions require an extensive or in-depth description of some social phenomenon. ${ }^{101}$ Survey methods may be used to gather this kind of data in conjunction with more descriptive 'what' data. 102 A case study methodology was therefore appropriate for this study because it involved

Robert Yin, Case Study Research: Design and Methods (SAGE, 4th ed, 2011) 18.

94 Bent Flyvbjerg, 'Case Study' in Norman Denzin and Yvonna Lincoln (eds), The SAGE Handbook of Qualitative Research (SAGE, 4th ed, 2011) 301.

95 Robert Stake, 'Qualitative Case Studies' in Norman Denzin and Yvonna Lincoln (eds), Strategies of Qualitative Inquiry (SAGE, 3 ${ }^{\text {rd }} \mathrm{ed}, 2008$ ) 119-20.

96 Flyvbjerg, 'Case Study', above n 94, 301.

97 Ibid 302.

98 Ibid 306.

99 Ibid 309.

100 Robert Stake, Multiple Case Study Analysis (Guilford Press, 2006) 1-4.

101 Yin, 'Case Study Research', above n 93, 4.

102 Ibid 9. 
students collaborating with staff in the creation of assessment, and described this process before analysing the results in terms of qualitative benefit for learning experience as perceived by students. ${ }^{103}$ The case study was descriptive in terms of showing what the students actually did, and explanatory in the sense of attempting to explain how and why they did it. ${ }^{104}$ The 'case' was the Semester 2, 2016 Evidence cohort at Queensland University of Technology and the phenomenon studied was participation in collaborative assessment.

The main research question for this study was whether allowing students to collaborate with staff in creating assessment would result in an enhanced learning experience as perceived by students. The method used to gather the data was two anonymous online surveys, which is appropriate to gather descriptive and explanatory data. ${ }^{105}$ All students in the subject (n $=710$ ) were invited to participate through email to facilitate representation of the cohort population. The surveys were purely voluntary and did not require any personal details to ensure anonymity. Identifying characteristics such as age or gender were also not required as these were not considered relevant for this specific research on the basis of the literature review. Both surveys received ethics approval. ${ }^{106}$ The questions for the online surveys were developed on the basis of the theories identified in the literature review. ${ }^{107}$ The questions were a combination of yes/no, Likert scale and open-ended questions. Students were reminded on multiple occasions to complete the surveys to maximise participation rates and the accuracy of the sample.

The first survey was released on Monday of Week 4 and remained open until Monday of Week 7. Its design was to seek student input on the content and structure of the essay component in the final exam. It asked students whether they preferred a single topic or a range of topics and who would choose them, provided an opportunity for students to select their preferred exam topic from a range of provided options, and allowed them to propose their own topics. The student responses were collated, and the essay question in the exam was developed on the basis of these responses. The question presented the students with a range of the four most popular topics, from which they were to choose one to write a short essay response. Though it might be objected that students were merely choosing essay topics for an exam question rather than 'creating assessment', their involvement in choosing the essay topics which formed part of the substance of the exam meant in effect that they were involved in creating their assessment through collaborating with staff.

The second online survey was released on Monday of Week 8 and remained open until Monday of Week 10. This survey investigated whether

103 Ibid 4.

104 See Robert Yin, Applications of Case Study Research (SAGE, $3^{\text {rd }}$ ed, 2012) xxii.

105 Ibid 9.

106 'Application and Approval' (Human Research Ethics Committee Application and Approval no 1600000605, Queensland University of Technology).

107 This is the preferred strategy according to Yin, 'Case Study Research', above n 93, 130. 
students felt that being involved in this process of co-creating assessment enhanced their learning experience by altering their attitude towards the assessment and the way they prepared. In particular, it asked them to reflect on the process of collaboration, specific questions relating to whether students felt aspects of their learning experience were or would be advanced by the process, and finally whether they would recommend that the process be adopted more broadly. The appendix below details the questions for both surveys. The next section outlines the results, which add to the existing evidence about the value and role of student involvement in assessment, particularly collaborating with students to create law assessment.

\section{Results}

For the first survey, 219 students responded, which is a response rate of $30.8 \%$.

\section{Figure 1}

Would you prefer to create one topic, or a range of topics students can

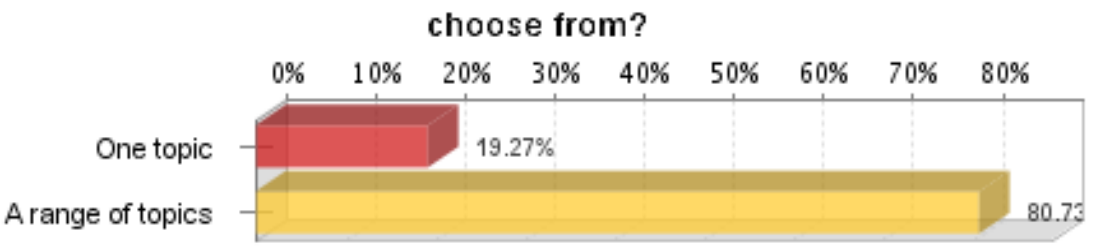

Figure 2

If there is a range of topics, would you prefer to choose all the topics or have staff choose some...

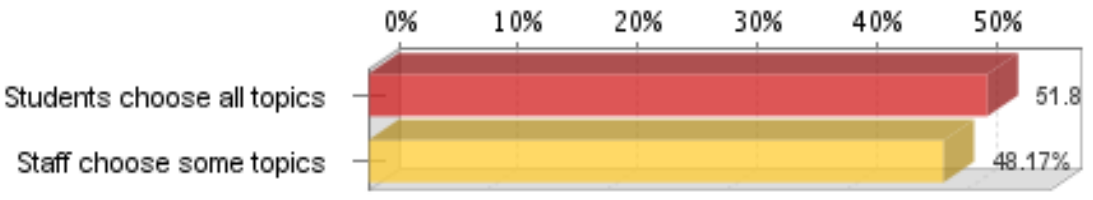

Figures 1 and 2 illustrate that $81 \%$ of students who responded indicated that would prefer a range of topics. $52 \%$ of students indicated that they would prefer to choose all topics of a range, while $48 \%$ indicated they would like staff to choose some topics of a range. Data arising from the 
students actually choosing the specific topics has been omitted from these results as this data is not relevant to answering the research question.

For the second survey, 80 students responded which is a response rate of $11.3 \%$.

Figure 3 (see Appendix for full questions and options)

\section{Reflecting on your recent experience, would you prefer to choose the}

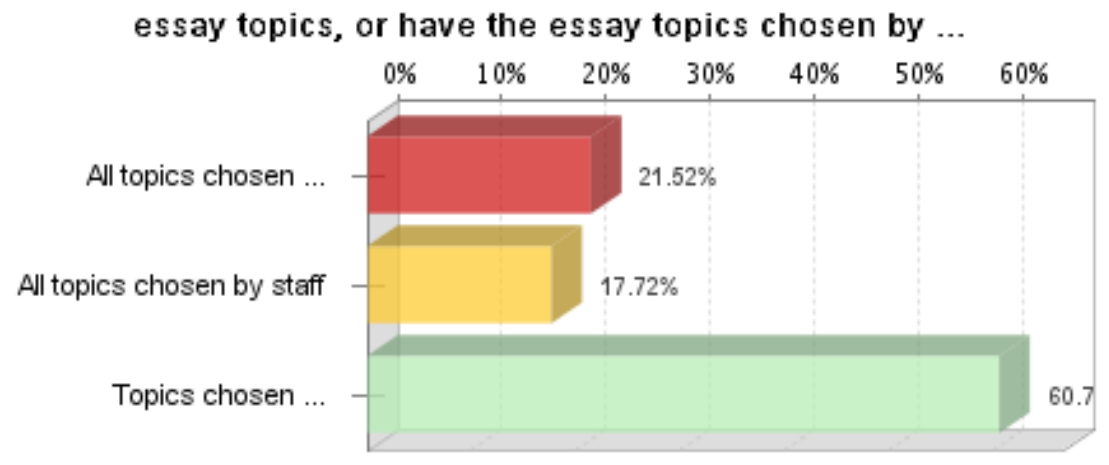

Figure 3 shows $61 \%$ of students who responded said that reflecting on this experience, they would prefer topics to be chosen by students and staff. $21 \%$ said that students should choose all topics and $18 \%$ said that staff should choose all topics.

In answering the open-ended questions, students noted that their 'input is important' and 'alleviates their anxiety'. The combination of staff and students 'ensures a degree of choice while also having questions that properly test what we've been taught by staff'. Some benefits noted by students were that they 'feel more motivated to achieve well as they have more control over their learning' and it 'allows a feeling of engagement' by 'creating a higher sense of "ownership"'. Collaborating on assessment 'gives students a sense of responsibility for their learning' and 'intrinsic motivation'. 'There is a sense of control and interaction which is likely to manifest with increased interest'. One student stated: 'If students were able to create their own assessment, I believe students would do better in the assessment. There is no doubt that if students know what will be on the exam, they will do better, but it will also encourage, I believe, a more in depth study of the chosen area.' However, a few students felt the process 'abdicated responsibility' from staff and that staff are 'specifically trained to devise and articulate appropriate questions', while students are more likely to 'make it easy for themselves'. 
Being involved in creating your own assessment changed your approach

to preparing for the assessment.

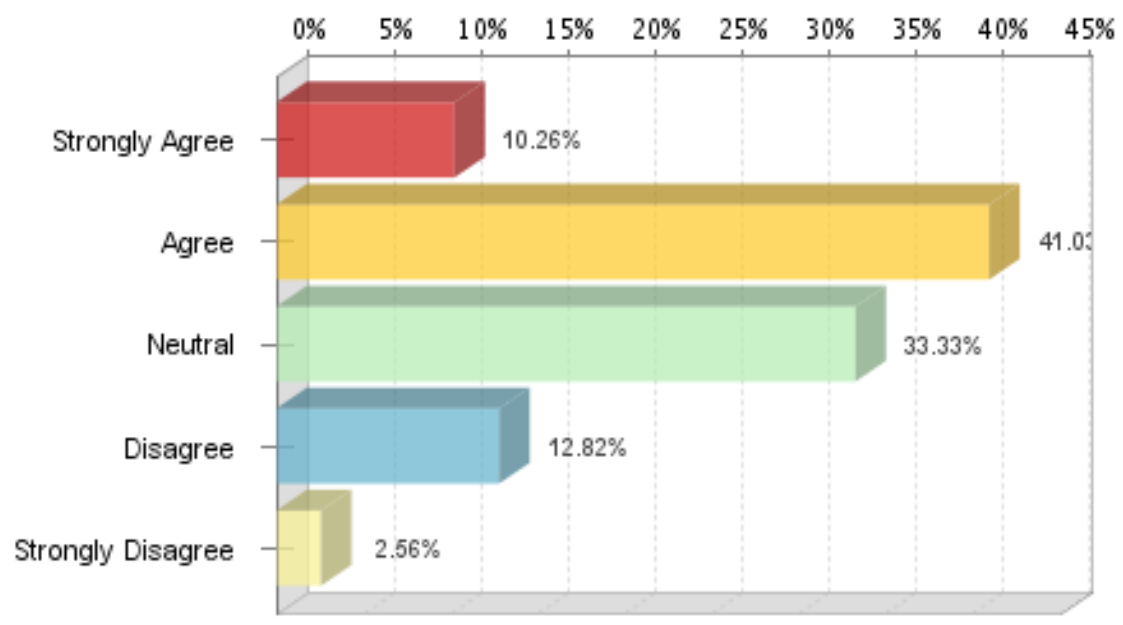

Figure 5

Being involved in creating your own assessment changed your attitude

towards the assessment.

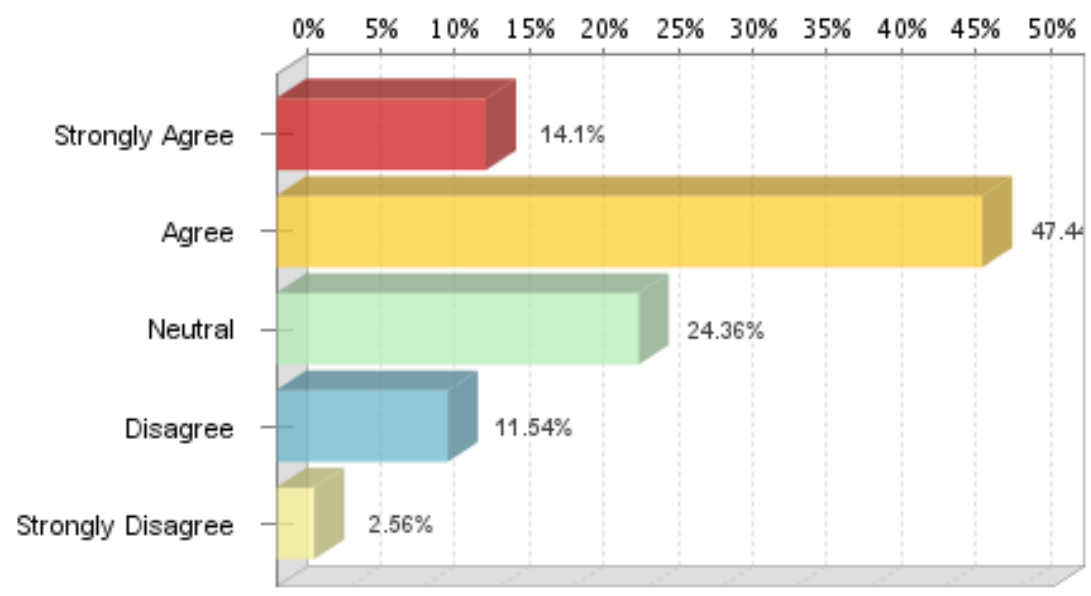

Figure 6 


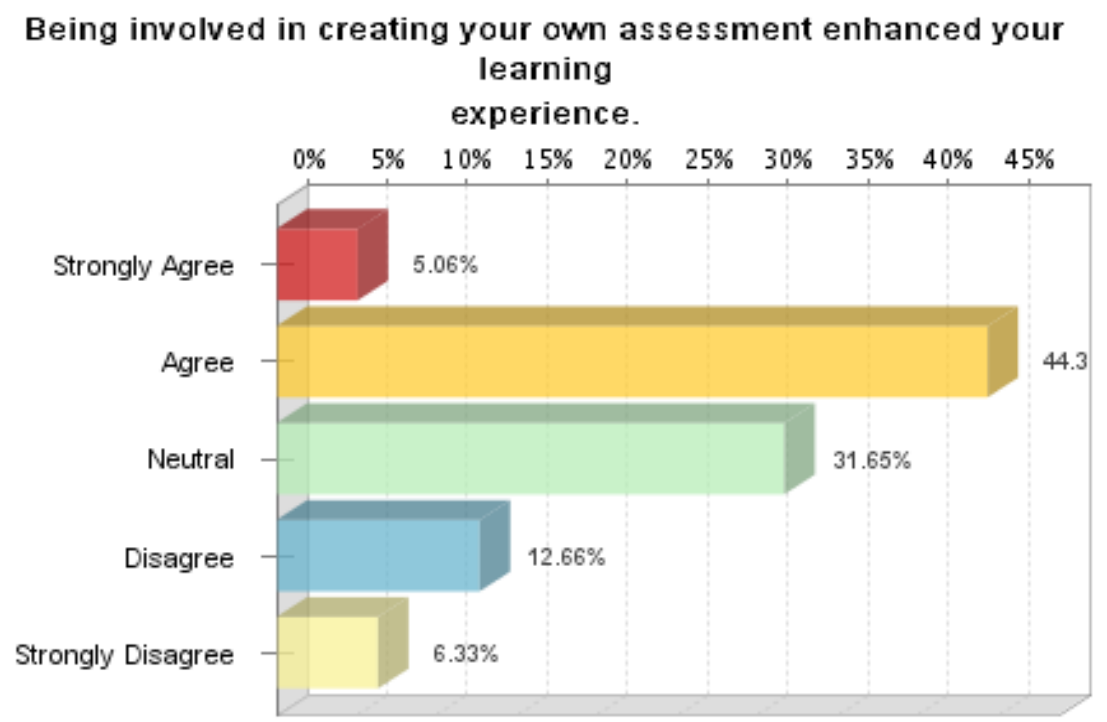

As shown in Figures 4-6, 51\% of students who responded agreed or strongly agreed that the collaborative approach changed their approach towards the assessment, with only $15 \%$ disagreeing or strongly disagreeing. $61 \%$ of students agreed or strongly agreed that the collaborative approach changed their attitude towards the assessment, with only $14 \%$ disagreeing or strongly disagreeing. $49 \%$ of students agreed or strongly agreed that the collaborative approach enhanced their learning experience, with $20 \%$ disagreeing or strongly disagreeing. These figures are contextualised by a significant neutral selection - 33\%, 24\% and 32\% for each issue respectively.

In general, students noted that by collaborating in the creation of assessment they would have greater 'focus' and 'therefore feel more confident' and have a 'positive attitude'. Students noted that 'motivation should be intrinsic' and they would 'probably be more inclined to prepare'. One student said 'because I actively sought to define the topic I wanted', they were 'more aware of and engaged in said topic'. Another student stated that they 'feel like they are having a more positive learning experience' and their 'learning experience is enhanced'. 
Figure 7

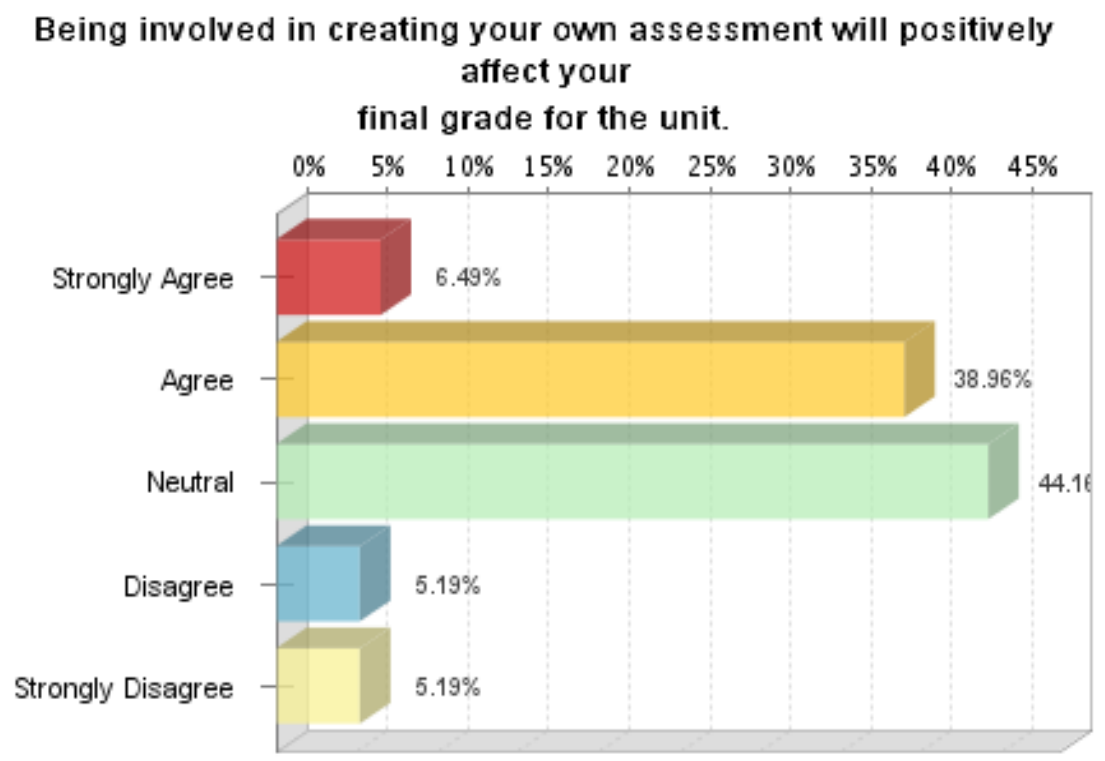

As seen in Figure 7, 46\% of students who responded agreed or strongly agreed that being involved in creating their own assessment would enhance their final grade for the unit. Only $10 \%$ disagreed or strongly disagreed. $44 \%$ of students were neutral on the question.

After results were finalised student marks for each question in the exam were ascertained. The exam was worth $50 \%$ of the student grade. $40 \%$ of this was two hypothetical scenarios worth $20 \%$ each. These were developed without collaboration with students. The remaining $10 \%$ was the essay question developed in collaboration with students. The average mark for the first hypothetical question was $12.7 / 20(63.5 \%)$. The average mark for the second hypothetical question was $10.2 / 20$ (51\%). This makes the average mark for the hypotheticals 22.9/40 (57\%). The average mark for the essay question was $7.3 / 10(73 \%)$. 
Figure 8

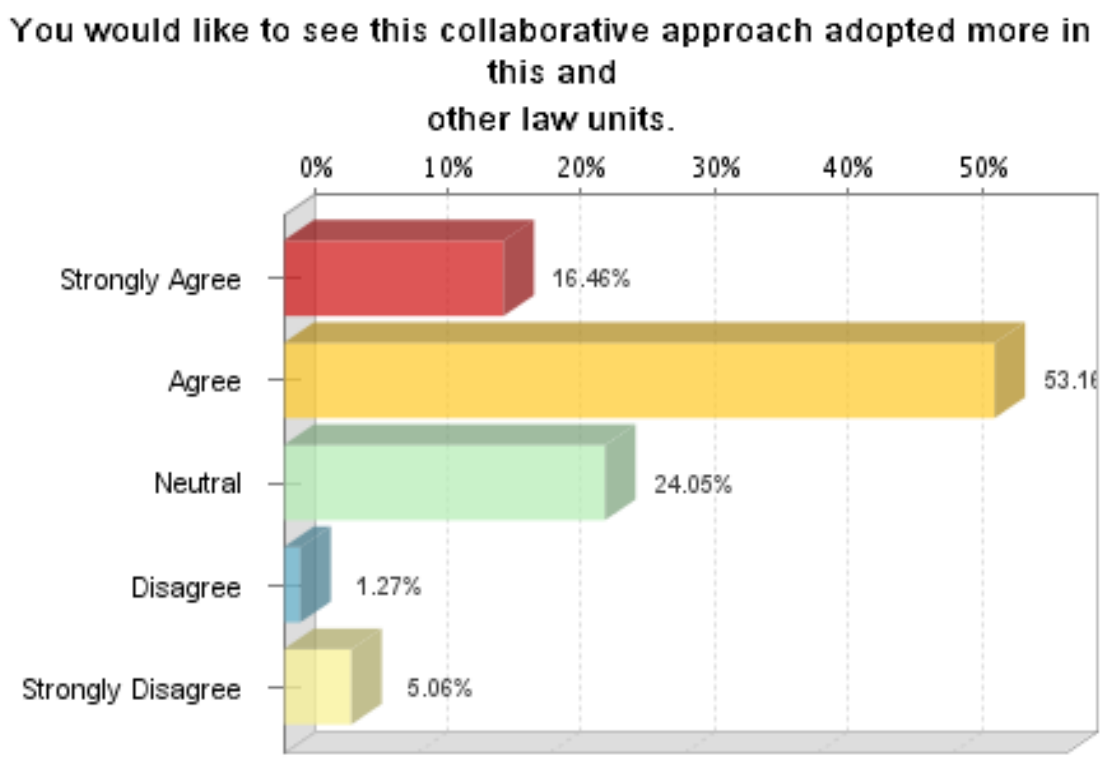

Finally, Figure 8 shows $70 \%$ of students agreed or strongly agreed that they would like to see this kind of collaborative assessment adopted in this and other law units. Only $6 \%$ disagreed or strongly disagreed, with $24 \%$ neutral.

Students noted that 'students like to have some degree of input and control but not too much' and that 'it was nice to feel consulted and the collaborative approach is something positive and engaging'. Another student observed:

The greater degree of engagement between staff and students in this subject has been, in my opinion, a positive influence on our learning experience. In particular, the opportunity to collaborate on the exam and the more progressive assessment structure encouraging legitimate engagement with evidence issues has indicated a greater level of concern with our learning compared to other law subjects taking the more 40/60 assessment approach. As such, I would like to see this approach taken in other law subjects.

\section{Analysis}

The quantitative data was analysed using basic descriptive statistics as indicated in the results. The graphs are derived directly from the graphing function in the KeySurvey software which was used to collect the data. The qualitative data in the form of student comments was observed and copied 
directly from the KeySurvey repository where the data is stored. 108 There are a number of limitations to this set of data which should be acknowledged. First, the data consists of students self-reporting their perceptions, so there could be bias or inaccuracies. ${ }^{109}$ Second, though there are over 700 students enrolled in the unit, only 80 responded to the second survey which examined substantive student perceptions about their learning experience, which is quite a low response - just over a third of the response rate to the first survey. As was explicitly suggested by a student, this may be because the second survey did not directly contribute to their assessment in the same way that the first survey did and so students felt less inclined to devote time to it. ${ }^{110}$ However, 80 students is a significant sample size for a relatively homogenous group such as students enrolled in a specific subject.

There were a considerable number of neutral opinions which affected the data, ranging from approximately one-quarter to nearly half of responses to the various questions. The surveys were released relatively early in the semester due to administrative and institutional constraints, and students attributed their uncertainty (manifested as neutrality) to the fact that it was too early in the semester for them to meaningfully pick exam topics and to evaluate how this process affected their learning. They also had not yet seen how their input had affected the exam or their results. To circumvent the large number of neutral opinions, a more effective approach would be to have both surveys occur later in the semester so students have a better idea of what kind of essay topics they are interested in and a better idea of how the collaborative process affected their approach to the assessment and their learning experience. This occurred in an ad hoc way by asking the students to comment on their experience of the collaborative process in their normal subject and teaching staff evaluations released at the end of semester during the study and exam period. The qualitative responses in these surveys ('Insight' and 'Student Perceptions of Teaching') from students corroborated their responses in the earlier surveys and with much more certainty. Students stated that it was a 'great idea' and they 'really liked being able to select their own essay question' despite being 'initially a bit cynical'. Other students observed that 'helping choose the topic made it feel as though it wouldn't be such a daunting exam.'

More substantively, students consistently noted that collaborating to create the essay topics helped them engage more critically with the material, producing deeper learning:

108 See Lee Epstein and Andrew D Martin, 'Quantitative Approaches to Empirical Legal Research' in Peter Cane and Herbert Kritzer (eds), The Oxford Handbook of Empirical Legal Research (Oxford University Press, 2010) 901.

109 See, eg, Katrien Struyven, Filip Dochy and Steven Janssens, 'Students' Perceptions about New Modes of Assessment in Higher Education: A Review' in Mien Segers, Filip Dochy and Eduardo Cascallar (eds), Optimising New Modes of Assessment: In Search of Qualities and Standards (Springer, 2003) 171.

110 Graham Gibbs, 'How Assessment Frames Student Learning' in Cordelia Bryan and Karen Clegg (eds), Innovative Assessment in Higher Education (Routledge, 2006) 23. 
'This has allowed me deeply interact with an essay topic rather than assigning roughly 20 minutes in the exam to broad-brush an area of Evidence law. This is the least stressed I have felt before an exam.'

'I really appreciated the opportunity you gave us to have an input on the essay topic for the exam. It allowed me to consider in more depth what the underlying concepts were before I entered the exam room, rather than other exams which require an essay question, where I consider the concept for a grand total of 2 minutes - If that!'

'I am very thankful for the advice on structuring the exam answers and the collaboration with creating the exam essay question and being told it prior to the exam so I can critically think about my answer rather than rambling on about nothing under exam pressure.'

The final comment raises a potential complication. In addition to students being able to collaborate to create the essay question and topics, the topics were released in advance of the exam so they could choose a topic and prepare a response prior to entering the exam environment. ${ }^{111}$ Many students expressed approval for this because it would help them critically engage with the question. It is not known whether this has impacted on the results in the sense that the results could merely be due to the fact that the topics were released prior to the exam, rather than the fact the students collaborated with staff to create the questions (or it could be a combination of both). One student even said that 'the biggest difference was in getting essay topics in advance, allowing me to prepare my response.' Further studies would be required to determine the relationship between these variables and the nature of any impact on the outcome.

On that note, a further limitation is this is in effect a one-shot case study. There is nothing for this data to compare against for the moment except the other anecdotal accounts provided by students. This implies there should be further studies, including control studies and repeat studies, to confirm the reliability and validity of the data. ${ }^{112}$ These studies could give students the opportunity to choose between essay topics which they have not contributed to, or examine a situation where a single topic is chosen by staff. The topic/s should be released in advance so that the extent of collaboration, choice and control by students is the dependent variable. The research could also be strengthened by undertaking the same activities with different cohorts of students over a number of years and/or different subjects at the same institution or different institutions. In this sense, the research in its current state could be viewed as a pilot study to inform further research.

111 This approach also raises the possibility of plagiarism in the sense that students know the topics so could collude in pre-writing essay answers. Informal discussions arising out of a presentation to colleagues indicated there is no easy answer to this, but the potential for collusion is minimised by multiple essay topics and multiple valid approaches within those topics, and impact of any collusion is minimal since it is only worth $10 \%$ of the student's final grade.

112 See, eg, Royce Singleton and Bruce Straits, Approaches to Social Research (Oxford, $5^{\text {th }}$ ed, 2010) 235 . 
Bearing these limitations in mind, the data provides evidence that collaborating with students to create law assessment in a subject will result in students believing their learning has been enhanced in that subject. A majority of students who responded (respondents) agreed or strongly agreed that when they had a choice and input into the assessment process, they felt more engaged and more confident such that their learning experience in the subject was enriched. This agrees with the literature in general and in law specifically. ${ }^{113}$ The perception of enhanced learning experience through collaboration may be supported by the actual results. On average students did significantly better in the essay question (73\%) than in the hypotheticals (57\%). On the other hand, breaking down each question individually, though the essay result is still higher, there is an approximately equal disparity in marks between all three questions. This raises the possibility that the difference is not related to the collaborative process, and as suggested above, more research would be needed to confirm this and the impact of other variables such as the early release of exam topics.

Nevertheless, as the results indicate, students who responded very clearly preferred to have some degree of autonomy, independence and choice when it comes to the content of assessment. For example, an overwhelming majority of respondents preferred a range of topics to choose from, and a significant majority of respondents preferred to be involved in choosing the topic options. The substantive comments by respondents show that the fact they had some control made them feel like they had ownership over their learning, which helped them to engage and be intrinsically motivated. In accordance with self-determination theory, the feedback from respondents indicated that giving them more autonomy in the form of allowing them to choose essay topics on the exam resulted in them feeling more positive about the exam and produced deeper learning and mastery of the topics chosen. ${ }^{114}$ A significant majority of respondents suggested that they would like to see this kind of collaborative approach adopted in this and other law units, which corroborates the conclusion Hess reaches. ${ }^{115}$

Comparing Figures 2 and 3 (acknowledging that the survey questions and answer options are not equivalent), after reflecting on their experience of the process, it appears that respondents may be more willing to have topics chosen by a combination of staff and students, rather than just having all topics chosen by students or staff. This contrasted with respondent views prior to the process, which indicated that a slim majority of students wanted to choose all their own topics. Though this must be taken as

113 See, eg, Robinson and Udall, above n 40, 94; Hess, 'Heads and Hearts', above n 78, 96-8.

114 See, eg, Field, Duffy and Huggins, above n 70, 26, 28-9; Huggins, 'Autonomy Supportive Curriculum Design', above n 71; Watson and Field, above n 18, 408-9; Brown, Bull and Pendlebury, above n 17, 15-16; Niemiec and Ryan, 'Self-determination Theory', above n 10; Sheldon and Krieger, above n 70.

115 Hess, 'Heads and Hearts', above n 78, 96-7. 
speculation, it is possible to view the transformation as a case example of the dialogue developing between students and teachers, and students being empowered to critically evaluate pedagogical approaches through exercising their critical judgment. 116 Specifically, the suggestion is that student views may have been transformed by the collaborative process and students were able to reflect on the process and consequently realised the benefits of the process after reflecting. This suggestion agrees with the results noted from the later 'Insight' and 'Student Perceptions of Teaching' surveys.

Interestingly, despite the apparent preference for a degree of control in the assessment process, many students were reluctant to receive full control over their assessment. This is shown by the almost even split in Figure 2 when students are asked whether they should choose all the topics, or whether staff should choose some, and the small minority in Figure 3 who wished to have students choose all essay topics. At the extreme level, one student felt that this collaborative process was an abdication of responsibility on the part of staff, and other students indicated that since staff are experts in the content and assessment process, staff should continue to have overall control to avoid the assessment becoming too easy. This preference for involvement, but not total control, is not explicitly reflected in the literature. However, there are indications in the literature that students desire collaboration more than complete control because they do not perceive their own abilities and knowledge to be sufficient for complete control (and some students may consciously or unconsciously make the assessment easier), and they do not like having power over other students. ${ }^{117}$ This also suggests that minimising the power differential between students and staff should not result in students having complete power over staff or other students. Instead, as Hess argues, the key approach is to 'share responsibility'. ${ }^{118}$ Thus, this article extends the work of Hess and others by adding to the evidence that students desire involvement in assessment through collaboration, because students perceive this involvement as collapsing an intimidating power differential and as ultimately enhancing their learning outcomes because they are more confident and engaged.

\section{Conclusion}

This article sought to add to the literature on collaborative assessment enhancing learning experience and extend it to the creation of assessment content in a law context. While further studies are needed due to limitations of the data, the results indicate that many students welcome some control and input in the content of assessment because it helps them engage more

116 Falchikov, 'Improving Assessment', above n 24, 62, 127, 151-2; Bryan and Clegg, above n 41, 225; Leach, Neutze and Zepke, above n 23, 296.

117 McConnell, above n 23, 82; Brew, above n 38, 161; Falchikov, 'Improving Assessment', above n 24, 67, 127; Huggins, Kift and Field, above n 89, 194.

118 Hess, 'Heads and Hearts', above n 78, 96. 
critically and confidently. However, these students also felt that staff should retain overall oversight to ensure that the assessment is properly rigorous. Therefore, pending further research, the article suggests that collaborating with students to create law assessment is a plausible option for enhancing engagement, motivation and learning experience, on the condition that staff remain in overall control to ensure the assessment is appropriately robust.

\section{Appendix}

\section{Survey 1: Survey of Students on Ideas for the Essay Topic in} the Exam

1. Would you prefer to create one topic, or a range of topics students can choose from?

2. If there is a range of topics, would you prefer to choose all the topics or have staff choose some of the topics?

3. What follows are some potential topics. Please select any which you would want to be the essay topic/an essay topic in the exam.

4. The rationale for the rules of evidence - truth, justice or neither?

5. 'All presumptive evidence of felony should be admitted cautiously; for the law holds it better that ten guilty persons escape, than that one innocent party suffer.' Do you agree? Why or why not?

6. Resolving conflicting duties between the client and the court.

7. Is the relevance threshold too low or high?

8. Has the hearsay rule and its many exceptions become too complicated? Is reform required?

9. Is the test for admitting similar fact evidence too stringent?

10. Should a person be convicted based entirely on circumstantial evidence?

11. Who is really an expert? Does the law of opinion evidence need updating?

12. Please suggest any other topics which you would want to be an essay topic in the exam.

\section{Survey 2: Survey of Student Experience in Collaborating with Staff to Create Law Assessment}

1. Reflecting on your recent experience, would you prefer to choose the essay topics (all topics chosen by students), or have the essay topics chosen by staff (all topics chosen by staff), or a combination of both (all topics chosen by both students and staff)? Why?

2. Explain what you believe to be any benefits of being involved in creating your own assessment.

3. Explain what you believe to be any disadvantages of being involved in creating your own assessment.

4. Did being involved in creating your own assessment change your approach to preparing for the assessment? (Likert scale) 
5. Explain your answer to 4.

6. Did being involved in creating your own assessment change your attitude towards the assessment? (Likert scale)

7. Explain your answer to 6.

8. Do you feel that being involved in creating your own assessment enhanced your learning experience? (Likert scale)

9. Why or why not?

10. Do you feel that being involved in creating your own assessment will affect your final grade for the unit? (Likert scale)

11. If so, how?

12. Would you like to see this approach adopted more in this and other law units? Why or why not?

13. Please provide any other comments 